DOI:

\title{
Minör kafa travmalarında anormal kranial bilgisayarlı tomografi saptamada yüksek risk faktörlerinin belirlenmesi
}

\author{
Determination of high risk factors for detection of abnormal cranial computed tomography in \\ minor head injury
}

Erkan ÇOBAN, Gözde ŞİMŞEK ŞEN, Özlem GÜNEYSEL

\section{ÖZET}

Amaç: Minör kafa travmalı erişkin hastaların epidemiyolojik analizini yaparak, bu hastalar içinden kranial bilgisayarlı tomografi (BT) çekimi için yüksek riskli grupları tespit etmektir.

Hastalar ve Yöntem: Hastanemiz Acil Tıp Kliniği'ne minör kafa travmasi nedeniyle Ocak 2012-Mart 2012 tarihleri arasında başvuran 450 hasta prospektif, gözlemsel olarak incelendi.

Bulgular: Olguların 126's1 (\%28) kadın, 324'dü (\%72) erkekti ve yaş ortalamaları $40,99 \pm 17,87$ 'idi. Olguların travma nedeni olarak motorlu araç kazaları, düşmeler ve darp ilk üç sırayı oluşturuyordu. Kafa kemik kırığg saptanan olguların en sık travma nedeni araç dışı trafik kazası (ADTK) ve darp iken; travmatik beyin yaralanması (TBY) saptanan olguların en sik travma nedeni yüksekten düşme olarak bulunmuştur. Olguların \% 73,6 (n=331)'sına kranial BT çekilmiştir. Anormal kranial BT oranı \%13 olarak saptanmıştır. Lineer fraktür $(\% 34,9)$, subdural hematom $(\% 25,6)$ ve subaraknoid kanama $(\% 16,3)$ en s1k tespit edilen anormal kranial BT bulgularıdır.

Sonuç: Glasgow koma skala (GKS) skorunun 14 olması, üçten fazla kusma ve skalp laserasyonu anormal kranial BT'nin tahmini açısından, yüksek risk oluşturduğu saptandı. Cinsiyet, yaş, travma nedeni, üçten fazla kusma dışındaki başvuru anındaki şikayetler, skalp laserasyonu dışındaki fizik muayene bulguları, alkol, antikoagulan alımı ile anormal kranial BT'nin saptanması arasında istatiksel olarak anlamlı ilişki tespit edilmedi.

Anahtar kelimeler: Kafa travması, Erişkin, Minör, Kranial BT bulgusu

Erkan Çoban (凶)

Acil Servis, Gebze Fatih Devlet Hastanesi, Kocaeli, Türkiye

e-mail:drerkan_12@hotmail.com

Gözde Şimşek Şen, Özlem Güneysel

Acil Tıp Kliniği, Dr. Lütfi Kırdar Eğitim ve Araşstırma Hastanesi, İstanbul, Türkiye

Gönderilme/Submitted: 23.09.2014

Kabul/Accepted: 08.12 .2014

\section{ABSTRACT}

Objectives: This study analyzed the epidemiology of adult cases with minor head trauma in order to identify the high risk groups for scanning by cranial computed tomography (CT).

Patients and Methods: We conducted a prospective observational study. This included 450 patients who had been seen at our Emergency Clinic and had experienced a minor head trauma between January 2012 and March 2012.

Results: One hundred and twenty six (28\%) of the patients were women and 324 (72\%) were men. The mean age was $40.99 \pm 17.87$ years. Leading trauma mechanisms were motor vehicle accidents, followed by falls and violence. Accidents not involving vehicles and violence were the most frequent causes for trauma in patients with a skull fracture; falls from a height were the most common cause in patients with traumatic brain injury (TBI). Cranial CT scans were performed in $73.6 \%(n=331)$ of the cases. Among CT scans, $13 \%$ were interpreted as abnormal. The most frequent abnormal CT findings included linear fracture (34.9\%), subdural hematoma (25.6\%) and subarachnoid hemorrhage (16.3\%).

Conclusion: The Glasgow coma scale (GCS) score of 14, vomiting more than 3 times and scalp laceration were predictors for a high risk of an abnormal cranial CT. There was no statistically significant relationship between an abnormal CT scan and gender, cause of trauma, complaints at presentation other than vomiting more than 3 times, physical examination findings other than scalp laceration, alcohol or anticoagulant use.

Keywords: Head trauma, Adult, Minor, Cranial CT findings

\section{Giriş}

Kafa travmaları, ciddi morbidite ve mortalite sebebi olarak önlenebilir olmaları açısından değerlendirilmesi gereken sosyoekonomik bir sorundur. Özellikle, az gelişmiş ve gelişmekte olan ülkelerde, genç nüfusta, ölüm sebepleri arasinda ilk sirada travmalar ve bunların da yarıdan fazlasında kafa travmaları yer almaktadır [1]. 
Acil servise başvuran kafa travmalarının \%89,1'ini minör kafa travmaları oluşturmaktadır [2] . Glasgow koma skalası (GKS) skoru 15 olan travma hastaları tüm hafif kafa travmalı hastaların \% 63-94'ünü oluşturmaktadır. Bu hastalarda intrakraniyal patoloji s1klığ $1 \%$ 4-8'dir [3].

Kranial bilgisayarlı tomografi (BT)'nin yaygın olarak kullanılmasından sonra minör kafa travmalı olgulara yaklaşım özel önem kazanmıştır. Sayıca çok fazla hasta olması nedeniyle bu hastaların tamamına kranial BT çekmek ülke ekonomisine ciddi bir yük getirmektedir. Ayrıca yüksek doz radyasyon diğer bir sıkıntı oluşturan durumdur. Öte yandan hasta sayısı bu kadar yüksek olmasına rağmen, bu hastaların sadece küçük bir grubunda intrakranial patoloji saptanmaktadır.

Biz bu çalışmada, Dr. Lütfi Kırdar Kartal Eğitim ve Araştırma Hastanesi Acil Tip Kliniği'ne minör kafa travması nedeniyle başvuran hastalarda anormal kranial BT prevalansını değerlendirmeyi ve kranial BT ihtiyacını ortaya koyabilecek klinik değişkenlerin var olup olmadıklarını saptamayı hedefledik. Bulgularımızı minör kafa travmaları ile ilgili şu ana kadar yapılmış olan çalışmalar ile birlikte değerlendirdik.

\section{Hastalar ve Yöntem}

Bu çalışma, Dr. Lütfi Kırdar Kartal Eğitim ve Araştırma Hastanesi Bilimsel Araştırma Değerlendirme Kurulu'ndan etik onayı alındıktan sonra 15 Ocak 2012 - 15 Mart 2012 tarihleri arasında Acil Tip Kliniği'ne minör kafa travması nedeniyle başvuran 450 hasta dahil edilerek yapildı. Bulgular prospektif, gözlemsel olarak kaydedildi.

On altı yaş üstü erişkin, GKS skoru 14 veya 15 olan ve kranial BT çekilen minör kafa travmalı hastalar çalışmaya alınd.

On altı yaşından küçük, travma mekanizması kesicidelici alet veya ateşli silah yaralanması olan hastalar çalışmaya dâhil edilmedi.

Hastaların yaşı, cinsiyeti, travma nedeni, şikayeti, fizik muayene bulgusu, GKS's1 ve ek durum (antikoagulan alımı, ilaç intoksikasyonu, alkol alımı, şant veya hemofili öyküsü) varlığının kranial BT'de patolojik bulgu saptanması arasındaki istatistiksel ilişki incelendi.

Çalışmamız, prospektif, gözlemsel olduğundan kranial BT çekimine hastaya bakan klinisyen karar vermiştir ve kranial BT çekimi öncesi herhangi bir kriter kullanılarak klinisyen yönlendirilmemiştir.

İstatistiksel analizler için NCSS (Number Cruncher Statistical System) 2007\&PASS (Power Analysis and Sample Size) 2008 Statistical Software (Utah, USA) programı kullanılmıştır.

\section{Bulgular}

Çalışma, 15 Ocak 2012-15 Mart 2012 tarihleri arasında Dr. Lütfi Kırdar Eğitim ve Araştırma Hastanesi Acil Tıp Kliniği'nde \%28,0'i (n=126) kadın, \%72,0'si (n=324) erkek olmak üzere toplam 450 olgu ile yapılmıştır. Olguların yaşları 16 ile 89 arasında değişmekte olup, ortalama $40,99 \pm 17,87$ ylldır.

Olguların, \%84,5'ü $(n=380)$ taburcu edilmiş, \%9,3'ü $(n=42)$ ise gözlem altına alınmıştır. Gözlem altına alınan olguların \%8,2'si $(\mathrm{n}=37)$ sonradan taburcu edilmiştir. Olguların \%6,2'si ( $\mathrm{n}=28)$ hastaneye yatırılmıştır. Hastaneye yatırılan olguların $\% 0,7$ 'si $(n=3)$ opere edilmiştir.

Olguların, \%73,6'sında ( $\mathrm{n}=331$ ) kranial BT çekilirken, \%26,4'ünde ( $\mathrm{n}=119)$ çekilmemiştir. Kranial BT çekilen 331 olgudan \%87,0'sinde ( $\mathrm{n}=288$ ) patolojik bulgu görülmezken, \%13'ünde ( $\mathrm{n}=43$ ) görülmektedir (Tablo I). Kranial BT bulgusu bulunan olguların $\% 53,5$ 'inde $(\mathrm{n}=23)$ intrakranial yaralanma varken, $\% 46,5$ 'inde $(n=20)$ kafa kemik kırı̆ ${ }^{\prime}$ vardır.

Tablo I. Kranial BT bulgusuna ilişskin dağılımlar

\begin{tabular}{llcc}
\hline & & N & \% \\
\hline Kranial BT & Çekildi & 331 & 73,6 \\
& Çekilmedi & 119 & 26,4 \\
Kranial BT & Hayir & 288 & 87,0 \\
Bulgusu & Evet & 43 & 13,0 \\
\hline
\end{tabular}

Kafa kemik kırığı olanlar ile intrakranial yaralanma görülen olguların yüksekten düşme, basit düşme, araç dışı trafik kazası (ADTK), araç içi trafik kazası (AİTK), motosiklet kazası, darp, iş kazası ve diğer travma nedenleri görülme oranları arasında istatistiksel olarak anlamlı farklılık saptanmamıştır ( $>00,05)$ (Şekil 1, 2).

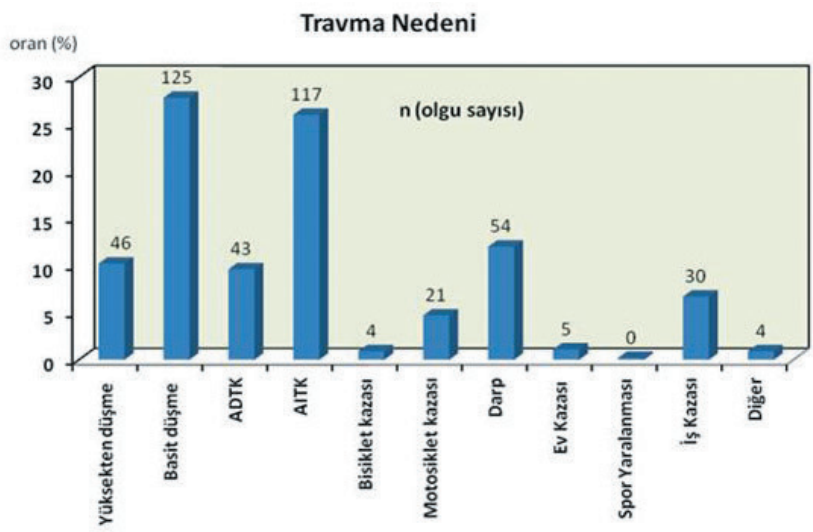

Şekil 1. Travma nedenleri 


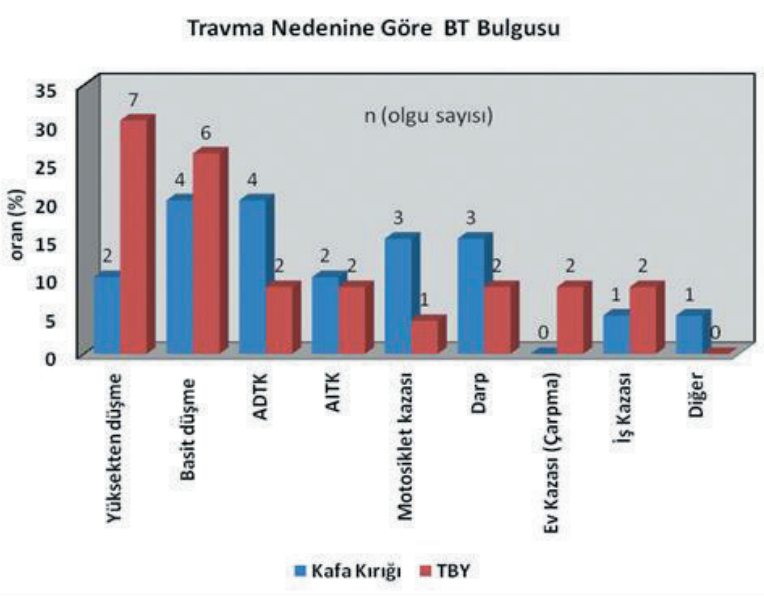

Şekil 2. Travma nedenine göre BT bulguları $\quad(\mathrm{TBY}=$ Travmatik beyin yaralanmas1)

Olguların şikayetleri incelendiğinde; kranial BT bulgusu durumuna göre olguların bulantı ve üç kereden az kusma, baş ağrısı, 5 dakikadan fazla bilinç kaybı, retrograd amnezi, anterograd amnezi ve nöbet şikayetleri görülme oranları arasında istatistiksel olarak anlamlı farklılık saptanmazken ( $>0,05)$; üçten fazla kusma şikayetinin görülme oranları arasında istatistiksel olarak ileri düzeyde anlamlı farklılık saptanmıştır $(\mathrm{p}<0,01)$. İntrakranial yaralanma görülen olgularda üçten fazla kusma şikayeti görülme oranı anlamlı şekilde yüksektir (Tablo II).

Tablo II. Travmatik beyin yaralanması (TBY) ve kafa kemik kırı̆̆ına göre şikayetlere ilişkin değerlendirmeler

\begin{tabular}{lccc}
\hline \multicolumn{4}{c}{ BT Bulgusu } \\
\multicolumn{1}{c}{ Şikayet } & Kafa Kırığı (n=20) & TBY $(\mathrm{n}=23)$ & $\mathrm{p}$ \\
& $\mathrm{n}(\%)$ & $\mathrm{n}(\%)$ & \\
\hline \hline $\begin{array}{l}\text { Bulantı ve üçten az } \\
\text { kusma }\end{array}$ & $9(\% 45,0)$ & $7(\% 30,4)$ & 1,24 \\
Baş ağrısı & $17(\% 85,0)$ & $20(\% 87,0)$ & 1.000 \\
Üçten fazla kusma & $2(\% 10,0)$ & $15(\% 65,2)$ & 0,001 \\
$\begin{array}{l}\text { Bilinç kaybı } \\
\text { (5 dk'dan fazla) }\end{array}$ & $1(\% 5,0)$ & $1(\% 4,3)$ & 1,000 \\
Retrograd amnezi & $1(\% 5,0)$ & $2(\% 8,7)$ & 1,000 \\
Anterograd amnezi & $0(\% 0)$ & $1(\% 4,3)$ & 1,000 \\
Nöbet geçirme & $0(\% 0)$ & $3(\% 13,0)$ & 0,236 \\
\hline
\end{tabular}

Kranial BT bulgusu görülme durumuna göre olgularda ek durum görülme (antikoagülan alımı, alkol alımı, şant varlığı) oranları arasında istatistiksel olarak anlamlı farklılık saptanmamıştır $(\mathrm{p}>0,05)$. Antikoagulan kullanımı oranları da kranial BT bulgularına göre anlamlı farklılık göstermemektedir ( $\mathrm{p}>0,05)$.

Anormal kranial BT saptanan olguların fizik muayene bulgularının olup olmaması arasında istatistiksel olarak anlamlı farklılık saptanmamıştır ( $>0,05)$.

Bir hastada fizik muayene bulgularından bir kaçı aynı anda saptanmakla beraber; skalp laserasyonu kafa kemik kırı̆g olan olgularda anlamlı düzeyde yüksek oranda saptanmıştır $(p<0,05)$. Sefal hematom ve abrazyon görülme oranları kranial BT bulgularına göre anlamlı farklılık göstermemektedir ( $p>0,05)$ (Tablo III).

Tablo III. Fizik muayene bulguları ile kranial BT bulgularının karşılaştırılması

\begin{tabular}{llcc}
\hline & \multicolumn{3}{c}{ BT Bulgusu } \\
Fizik Muayene & Kafa Kırı̆ $1(\mathrm{n}=20)$ & TBY $(\mathrm{n}=23)$ & $\mathrm{P}$ \\
& $\mathrm{n}(\%)$ & $\mathrm{n}(\%)$ & \\
\hline \hline Yok & $1(\% 5,0)$ & $3(\% 13,0)$ & 0,610 \\
Var & $19(\% 95)$ & $20(\% 87)$ & \\
\hline Skalp Laserasyonu & $8(\% 40,0)$ & $2(\% 8,7)$ & 0,039 \\
Sefal Hematom & $12(\% 60)$ & $13(\% 56,5)$ & 0,818 \\
Abrazyon & $2(\% 10,0)$ & $1(\% 4,3)$ & 0,590 \\
\hline
\end{tabular}

\section{Tartışma}

Tüm dünyada olduğu gibi ülkemizde de, kentleşme ve endüstrileşmenin ortaya koyduğu en ciddi sorunlardan biri travmalardır. Kafa travmalarına bağlı ölüm oranları, tüm travmalar içinde 1/3 oranında olduğu saptanmıştır [1].

Çalışmamıza 450 minör kafa travmalı hasta dahil edilmiştir. Erkek hastaların kadın hastalara oranı 2.57/1 idi. Literatürde yapılan çalışmalara göre erkeklerin kadınlara oranla daha sık kafa travmasına maruz kalması saptanmıştır $[1,4]$. Aygün ve arkadaşlarının yapmış olduğu çalışmada $\mathrm{E} / \mathrm{K}$ oranı $2.54 / 1$ olup; bizim çalışmamızdaki $\mathrm{E} / \mathrm{K}$ oranına yakındır [5]. Yine Mirzai'nin çalışmasında E/K oranı 2.49/1 dir [6]. Erkek nüfusun travmaya daha fazla maruz kalmasını; erkek cinsiyetin daha aktif bir yaşama sahip olması ve erkek nüfusun dış ortamda daha fazla bulunmasından kaynaklanabilir.

Olgularımızı travma nedenlerine göre sıraladığımızda motorlu araç kazaları, düşmeler ve darp ilk üç sırayı oluşturuyordu. Bulgularımız literatürde yapılmış olan diğer çalışmalarla uyumluluk arz ediyordu. Işık ve arkadaşlarının yapmış olduğu çalışmada en sık travma nedeni $\% 75$ oranı ile trafik kazaları olduğu saptanmıştır [1]. Mirzai'nin yapmış 
olduğu çalışmada da en sik travma nedeni \%59,8 ile trafik kazalarıdır [6]. Her iki çalışmada da trafik kazalarına bağlı başvuruların bu kadar yüksek oranda olmasının nedeni çevre il ve ilçelerden çok sayıda hasta sevkinin olması olarak yorumlanmıştır. Bizim oranımızın daha düşük (\%40,3) olmasının nedeni ise; İstanbul'da çok sayıda travma merkezinin bulunması ve buna bağlı olarak Acil Tıp Kliniği'mize sevk edilen minör kafa travmalı olgu sayısının daha az olması olabilir. Düşmelerin travma nedenleri arasında önemli bir paya sahip olmasını; Kartal çevresinde çok sayıda inşaat faaliyetlerin devam etmesi ve işçilerin yeterli koruyucu önlemleri almamasina bağlı olduğunu düşünüyoruz. Darp olaylarının fazla oranda yaşanmasının nedeni olarak, sosyokültürel düzeyin düşük olması ve şiddete eğilimin fazla olması akla gelmektedir.

Literatürde, minör kafa travmalı olgularda kranial BT'de patolojik bulgu saptama oranları oldukça farklılık göstermektedir. GKS skoru 15 olan minör kafa travmalarının yaklaşık \%5-15'inde anormal BT bulguları saptandığı literatürde belirtilmektedir [7]. Bazı çalışmalarda bu oranın anlamlı olarak yüksek $(\% 34,6)$ bulunduğu bildirilirken [5], Miller 1382 mimör kafa travmalı olguyu kapsayan çalışmasında kranial BT'de \%6,1 oranında kafa içi yaralanmayla uyumlu patolojik bulgu saptadığını bildirmiştir. $\mathrm{Bu}$ çalışmada patolojik BT bulgusu olarak beyin ödemi dikkate alınmamıştır [8]. Aygün'ün 78 olguluk çalışmasında pozitif BT bulgusu oranı $\% 34,6$ idi [5]. Boran'ın yapmış olduğu 371 olguluk çalışmasında GKS skoru 15 olan tüm hastalara kranial BT çekilmiş ve hastaların \%9,2'sinde patoloji saptanmıştır [4]. Pozitif BT oranlarının bu kadar değişken olması; başvuru esnasında hastaların GKS skoru dağılımına ve patolojik BT bulgusu olarak farklı kriterleri almalarından kaynaklanıyor olabilir.

Minör kafa travmalı hastaların hangilerine kranial BT çekmek gerektiği konusunda çalışmalar yayınlanmış ve protokoller önerilmiştir. Tüm klinik parametreler içinde GKS skoru en önemli parametredir. GKS skoru 14 olan hastalarda intrakranial lezyon saptanma oranının \%13-18'lerde olması bu hastalara kranial BT çekilmesi gerekliliğini haklı çıkartmaktadır ve bu konuda literatürde fikir ayrılıkları yoktur. Asıl fikir ayrılıkları GKS skoru 15 olan hastalar konusunda çıkmıştır [4]. Kafa travmalarında BT çekimi için kullanılan, Amerikan Acil Hekimler Birliği (American College of Emergency Physicians (ACEP)), Canada, New Orleans ve Nexus II kriterlerinin tümünde hastanın GKS skoru 15 olsa da tekrarlayan kusma, $\geq 65$ yaş, kafa tabanı fraktürünün klinik bulguları varlığı, koagülopati, tehlikeli mekanizma, fokal nörolojik defisit varlığında kranial BT çekilmesi önerilmektedir [9-11]. Çalışmamızda, pozitif BT oranının düşük saptanmasının nedeni olarak; hekimleri koruyan yeterli kanunların olmayışı ve medikolegal açıdan zor durumda kalmamak için hiçbir kriter gözetmeksizin kranial BT çekilmesi düşünüldü. Yüksek doz radyasyon ve yüksek maliyet nedeni ile gereksiz kranial BT çekimini sınırlamak için; hasta başvurularının fazla olduğu acil servislerin gözlem alanlarının arttırılması gerekmektedir. Yine hekimlerin medikolegal açıdan korunduğu yasal düzenlemeler yapılmalıdır.

Çalışmamızda kafa kemik kırığı ve intrakranial yaralanma olan olgular ile travma nedeni arasında istatistiksel ilişki saptanmamıştır ve literatür ile uyumludur $[8,12,13]$. Miller ve Gomez travma mekanizmasının travmatik intrakraniyal yaralanma için bir risk faktörü olmadığını belirtmişlerdir (8). Borczuk, motorlu araç ve bisiklet kazasına uğrayan çocukların intrakraniyal yaralanmaya daha fazla eğimli olduğunu saptarken; yetişkinlerde travma mekanizmasının intrakraniyal yaralanma ile ilişkisi olmadığını belirtmiş̧ir [13]. Ancak çalışmamızda kafa kemik kırığı saptanan olguların en sik travma nedeni ADTK ve darp iken; intrakranial yaralanma saptanan olguların en sik travma nedeni yüksekten düşme olarak bulunmuştur. Travma nedeni ADTK ve darp olan olguların kafa kemik kırığı, yüksekten düşme olguların ise intrakranial yaralanma açısından önem taşımaktadır. $\mathrm{Bu}$ travma nedenleri hekimin kranial BT çekimini etkileyebilir.

Çalışmamızda üçten fazla kusmanın pozitif BT için risk faktörü olduğunu saptadık. Miller, bulantı-kusmanın pozitif BT bulgusu için bir risk faktörü olduğunu belirtirken, diğer bazı yazarlar bunun aksini dile getirmişlerdir $[8,14,15]$. Tekrarlayan kusma atakları travma sonrası artan intrakraniyal basınca bağlı olabilir. Artan intrakraniyal basıncın intrakranial yaralanmaya işaret edebileceği muhtemeldir.

Bazı yazarlar posttravmatik amnezi ve bilinç kaybı tarifleyen hastalarda daha yüksek oranda patolojik BT bulgusu saptandığını ve bundan dolayı bunun bir risk faktörü olduğunu ifade etmişlerdir [16,17]. Diğer bazı yazarlar ise, bunun aksini belirtmişlerdir $[5,8,13]$. Literatürdeki bu farklı görüşler çalışma gruplarının farklılığından kaynaklanıyor olabilir. Amnezi ve bilinç kaybının anlamlı olduğunu söyleyen çalışmalardaki örneklem grubunda GKS skoru 13 olan hasta oranı fazla iken; bunun aksini söyleyen çalışmalarda bu oran çok daha azdır. Bizim çalışmamızda, amnezi ve bilinç kaybının pozitif BT'ye işaret edecek bulgular açısından istatiksel olarak anlam taşımamasını; bu öyküye sahip olgu sayısının az olmasından kaynaklandığını 
düşünüyoruz. GKS skoru 14-15 ve posttravmatik amnezi veya bilinç kaybına sahip daha büyük örneklem grubu ile ileri araştırmalar yapılması gereklidir.

\section{Sonuc}

Çalışmamızda, erişkin minör kafa travmalı hastalarda, GKS skorunun 14 olmasının, üçten fazla kusmanın ve skalp laserasyonunun bulunmasının anormal kranial BT'yi tahmin etmede önemli faktörler olduğunu, travma nedeninin, skalp laserasyonu dışındaki fizik muayene bulgularının, baş ağrısı, üçten az kusma, amnezi, posttravmatik nöbetin, alkol ve antikoagulan alımının ise anormal kranial BT'yi tahmin etmede önemli faktörler olmadığını saptadık.

\section{Kaynaklar}

1. Işık H, Bostancı U, Yıldız Ö, Özdemir C, Gökyar A. Kafa travması nedeniyle tedavi edilen 954 erişkin olgunun retrospektif değerlendirilmesi: Epidemiyolojik çalışma. Ulusal Travma Acil Cerrahi Dergisi 2011;17: 46-50. doi: 10.5505/ tjtes.2011.57431

2. Ro YS, Shin SD, Holmes JF, Song KJ, Park JO, Cho JS, Lee SC, Kim SC, Hong KJ, Park CB, Cha WC, Lee EJ, Kim YJ, Ahn KO, Ong ME. Traumatic Brain Injury Research Network of Korea (TBI Network). Comparison of clinical performance of cranial computed tomography rules in patients with minor head injury: a multicenter prospective study. Acad Emerg Med 2011; 18:597-604. doi: 10.1111/j.1553-2712.2011.01094.x.

3. Culotta VP, Sementilli ME, Gerold K, Watts CC. Clinicopathological heterogeneity in the classification of mild head injury. Neurosurgery 1996; 38:245-50.

4. Boran BO, Barut N, Akgün C, Çelikoğlu E, Bozbuğa M. Hafif kafa travmalı olgularda bilgisayarlı beyin tomografisi endikasyonları. Ulusal Travma Acil Cerrahi Dergisi 2005;11: 218-25.

5. Aygün D, Güven H, İncesu L, Şahin H, Doğanay Z, Altıntop L. Hafif kafa travmalı olguların kraniyal tomografisindeki patolojik bulgu sıklığının yaş grupları ve klinik ile korelasyonu. Ulusal Travma Acil Cerrahi Dergisi 2003; 9:129-33.

6. Mirzai H, Dinç G, Tekin İ. Hafif kafa travmalarında BT endikasyonunu belirlemede Miller kriterlerinin yeri. DEÜ Tıp Fakültesi Dergisi 2004; 18:158-63.
7. Heegaard WG, Biros MH. Head injury. In: Marx J A, editor. Rosen's Emergency Medicine Concepts and Clinical Practice. 8th edition. Philadelphia: Elsevier, 2014:339-67.

8. Miller EC, Derlet RW, Kinser D. Minor head trauma: Is computed tomography always necessary? Ann Emerg Med 1996; 27: 290-4. doi: http://dx.doi.org/10.1016/S01960644(96)70261-5

9. Jagoda AS, Bazarian JJ, Bruns JJ Jr, Cantrill SV, Gean AD, Howard PK, Ghajar J, Riggio S, Wright DW, Wears RL, Bakshy A, Burgess P, Wald MM, Whitson RR. American College of Emergency Physicians; Centers for Disease Control and Prevention. Clinical policy: neuroimaging and decisionmaking in adult mild traumatic brain injury in the acute setting. Ann Emerg Med 2008; 52:714-48. doi: 10.1016/j. annemergmed.2008.08.021.

10. Haydel MJ, Preston CA, Mills TJ, Luber S, Blaudeau E, DeBlieux PM. Indications for computed tomography in patients with minor head injury. N Engl J Med 2000; 343:10005. doi: 10.1056/NEJM200007133430204

11. Papa L1, Stiell IG, Clement CM, et al. Performance of the Canadian CT Head Rule and the New Orleans Criteria for predicting any traumatic intracranial injury on computed tomography in a United States Level I trauma center. Acad Emerg Med 2012; 19:2-10. doi: 10.1111/j.15532712.2011.01247.x.

12. Çete Y, Pekdemir M, Oktay C, Eray O, Bozan H, Ersoy F. Minör kafa travmas1 olan hastalarda bilgisayarlı beyin tomografisinin rolü. Ulus Travma Acil Cerrahi Derg 2001; 7: 189-94.

13. Borczuk P. Predictors of intracranial injury in patients with mild head trauma. Ann Emerg Med 1995;25:731-6. doi: http:// dx.doi.org/10.1016/S0196-0644(95)70199-0

14. Reinus WR, Zwemer FL. Clinical prediction of emergency cranial computed tomography results. Ann Emerg Med 1994; 23:1271-8. doi: http://dx.doi.org/10.1016/S01960644(94)70351-5

15. Schunk JE, Rodgerson JD, Woodward GA. The utility of head computed tomographic scanning in pediatric patients with normal neurologic examination in the emergency department. Pediatr Emerg Care 1996; 12:160-5.

16. Armağan E, Akköse Ş, Bulut M. Retrograd amnezi tek başına bilgisayarlı beyin tomografisi çektirme endikasyonu mudur? Ulus Travma Acil Cerrahi Derg. 1999;5: 274-6.

17. Stein SC, Ross SE. Mild head injury: a plea for routine early CT scanning. J Trauma 1992; 33:11-3. 